\title{
OPTICAL COHERENCE TOMOGRAPHY FINDINGS IN NONPROLIFERATIVE GROUP 2A IDIOPATHIC JUXTAFOVEAL RETINAL TELANGIECTASIS
}

STEVEN M. COHEN, MD,* MARK L. COHEN, MD $\dagger$

FAYSSAL EL-JABALI, BS, $\ddagger$ SCOTT E. PAUTLER, MD*

Purpose: To determine the optical coherence tomography (OCT) findings in eyes with group 2a idiopathic juxtafoveal retinal telangiectasis (IJRT).

Methods: Forty-one eyes of 22 patients with nonproliferative group 2a IJRT were examined. OCT testing including retinal topographic mapping and analysis, and horizontal and vertical line scans, was obtained on each eye.

Results: None of the 41 eyes had a thickened foveal center. The average center foveal thickness was $166 \mu \mathrm{m}(31-264 \mu \mathrm{m})$. Stage 1 eyes $(n=2)$ were normal fellow eyes in patients with contralateral group 2 a IJRT. Stage 2 eyes $(n=11)$ all had parafoveolar temporal graying and intraretinal temporal fluorescein leakage, but rarely had photoreceptor disruption (18\%) on OCT testing. Stage 3 eyes $(n=14)$ all had clinical and fluorescein findings similar to or more pronounced than stage 2 eyes. All stage 3 eyes also had one or more foveal cysts at various retinal depths on OCT. Most of these eyes $(86 \%)$ had photoreceptor disruption and outer retinal atrophy on OCT. Stage 4 eyes $(n=14)$ all had a black foveal or parafoveolar pigment plaque and intraretinal temporal fluorescein leakage. All stage 4 eyes had a hyper-reflective plaque with shadowing on OCT corresponding to the pigment plaque. Most of these eyes had one or more foveal cysts (64\%) and all of these eyes had photoreceptor disruption and outer retinal atrophy.

Conclusion: OCT helps in the staging of group 2a IJRT and reveals multiple retinal structural abnormalities.

RETINA 27:59-66, 2007

$\mathrm{P}$ atients with group $2 \mathrm{a}$ acquired idiopathic juxtafoveal retinal telangiectasis (IJRT) usually present with mild blurring of vision in one or both eyes in the fifth and sixth decades of life. ${ }^{1-6}$ They commonly have superficial parafoveolar retinal crystalline deposits, ${ }^{7}$ gray discoloration of the temporal parafoveolar

From the *Department of Ophthalmology, $\ddagger$ University of South Florida School of Medicine, Tampa; and the $\dagger$ Division of Neuropathology, University Hospitals of Cleveland and Case School of Medicine, Ohio.

The authors have no proprietary interest in this article.

Reprint requests: Steven M. Cohen, MD, 579 S. Duncan Ave., Clearwater, FL 33756; e-mail: scohen@hsc.usf.edu retina, and right-angle vessels with no exudation. These patients also can develop parafoveal intraretinal pigment migration similar to that seen in patients with retinitis pigmentosa. Fluorescein angiography in these eyes usually reveals temporal parafoveal telangiectatic vessels and intraretinal fluorescein leakage that spares the foveal center. ${ }^{1}$ These eyes can develop subretinal neovascularization originating from the juxtafoveal telangiectatic vessels. ${ }^{1-6,8}$ Gass classified group $2 \mathrm{a}$ IJRT into five stages based on slit lamp biomicroscopic and fluorescein angiographic findings.

Optical coherence tomography (OCT) is a noninva- 
Table 1. Findings in Eyes With Nonproliferative Group 2a IJRT

\begin{tabular}{lc}
\hline Method & \multicolumn{1}{c}{ Findings } \\
\hline Fundus examination & $\begin{array}{c}\text { Superficial retinal crystals, juxtafoveal telangiectasis, foveal cyst, foveal thinning, } \\
\text { black stellate foveal or parafoveal pigment plaque } \\
\text { Juxtafoveal telangiectasis with fluorescein leakage, hypofluorescence because of } \\
\text { blockage by pigment plaque } \\
\text { Focal hyper-reflective spots (crystals), outer retinal atrophy, foveal cyst(s) at all } \\
\text { depths, hyper-reflective plaque with shadow }\end{array}$ \\
\hline
\end{tabular}

IJRT = idiopathic juxtafoveal retinal telangiectasis.

sive commercially available retinal imaging technique that allows evaluation of retinal structures in vivo. ${ }^{9-13}$ OCT allows delineation of retinal structural abnormalities in patients with group 2a IJRT. ${ }^{11-13}$

We present OCT findings in 41 eyes of 22 patients with nonproliferative group 2a IJRT. We also incorporated the OCT findings into a staging of group $2 \mathrm{a}$ IJRT based on the pre-OCT Gass staging of this disease. We then discuss a plausible pathogenesis for this enigmatic disease.

\section{Patients and Methods}

A computer search located all consultation reports from two of the authors (S.M.C. and S.E.P.) from January 2002 to December 2005 containing the words "retinal telangiectasis." Each candidate's medical records, film fundus photographs, and film fluorescein angiograms were reviewed, and 26 patients with group 2a bilateral IJFT were identified (Table 1). Twenty-three of these patients underwent a comprehensive eye examination and OCT. OCT testing included retinal topographic mapping and analysis, and horizontal and vertical line scans. Five eyes with subretinal neovascularization were excluded from this study. Forty-one eyes with nonproliferative group 2a IJRT of 22 patients are presented in this report.

Staging of each eye was done using a combination of noncontact slit lamp biomicroscopy, film fundus photographs, film red-free photographs, film fluorescein angiograms, and vertical and horizontal OCT line scans through the fovea (Table 2).

\section{Results}

The patients' average age was 71 years (range 5289). Twelve of 22 patients were female. Median visual acuity was 20/40 (range 20/20-20/400) (Table 3). Twenty-five of the 41 eyes had visual acuity of 20/40 or better. Based on noncontact slit lamp biomicroscopy, fundus photographs, fluorescein angiograms, and OCT line scans, the 41 eyes were classified into four stages ${ }^{1,4}$ (Table 2).

Stage 1 eyes $(n=2)$, the normal fellow eyes of patients with more advanced IJRT in the other eye, had normal OCT scans. The average foveal thickness was $194 \mu \mathrm{m}$ (Table 3).

Stage 2 eyes $(n=11)$ had a slight graying and loss of transparency of the parafoveolar retina (100\%), parafoveolar telangiectasis, and late temporal fluorescein leakage $(100 \%)$ (Table 3). Eyes with foveal hyporeflective zones on OCT were excluded from this group. Four $(36 \%)$ of these eyes also had superficial retinal crystals. The mean foveal thickness in these eyes was $195 \mu \mathrm{m}(156-232 \mu \mathrm{m})$. OCT line scans showed photoreceptor disruption and outer retinal atrophy in two eyes (Figure 1, Table 3 ).

Stage 3 eyes $(n=14)$ had dilated and blunted right-angle vessels $(69 \%)$ in addition to graying of the temporal retina $(100 \%)$, retinal crystals $(57 \%)$, and telangiectasis seen with slit lamp biomicroscopy and fluorescein angiography (Table 3). Rarely, a circular abnormality was seen in the fovea $(29 \%)$ that looked like a lamellar macular hole and correlated with the OCT finding of a foveal cyst. Eyes with foveal hyporeflective zones were included in this group. Eyes with a black, superficial, stellate plaque, usually temporal to the fovea, were excluded from this group (Table 2). The mean foveal thickness in these eyes was $210 \mu \mathrm{m}(156-232 \mu \mathrm{m})$. Optical coherence tomography showed a foveal cyst in all of these eyes with an average width of $250 \mu \mathrm{m}(50-700 \mu \mathrm{m})$ and an average height of $75 \mu \mathrm{m}(50-150 \mu \mathrm{m})$. Most of these

Table 2. Staging of Eyes With Nonproliferative Group 2a IJRT

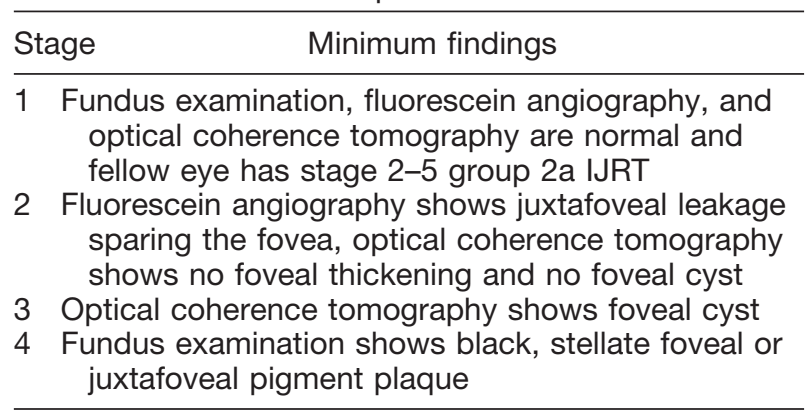

IJRT = idiopathic juxtafoveal retinal telangiectasis. 


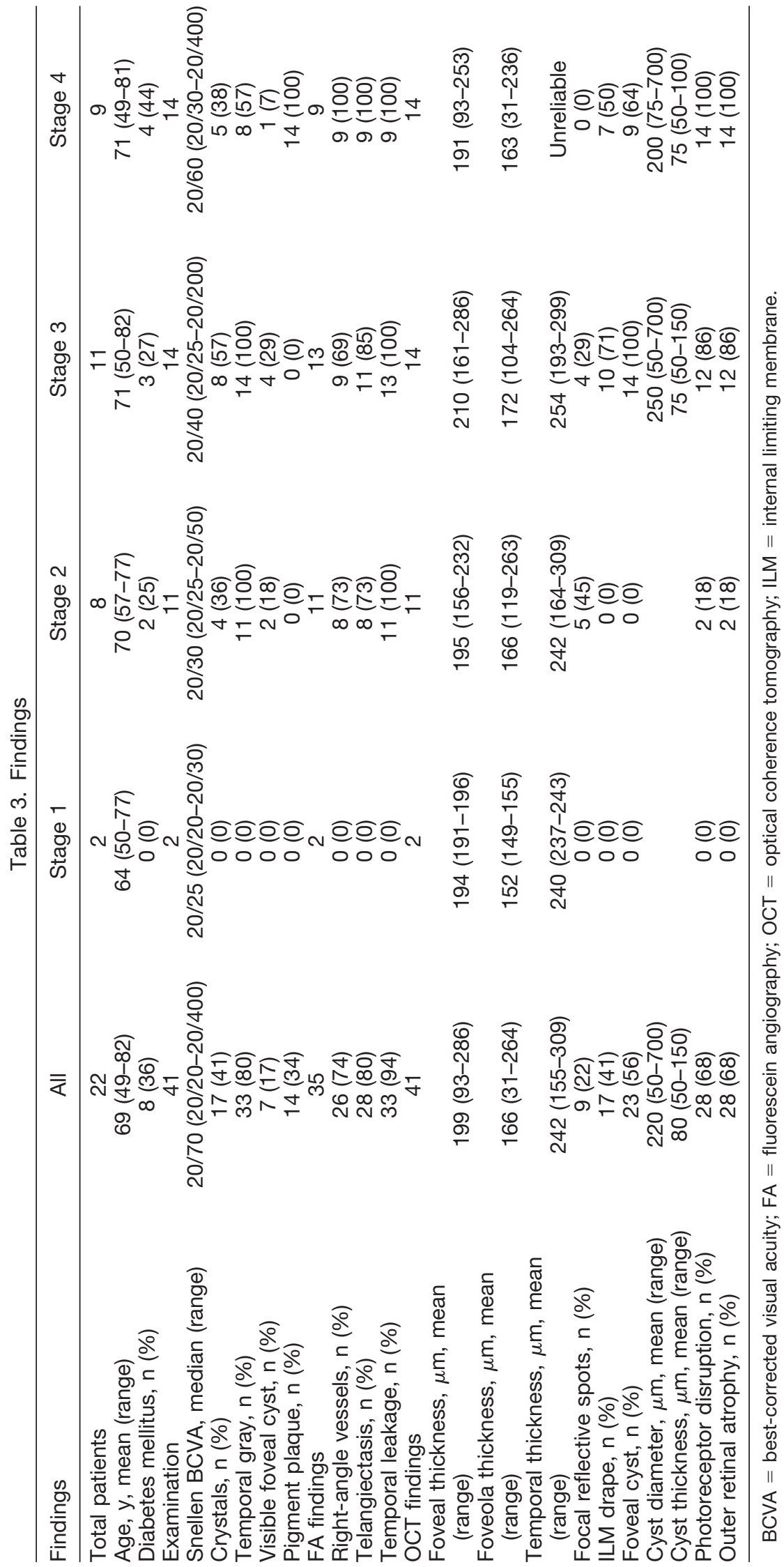



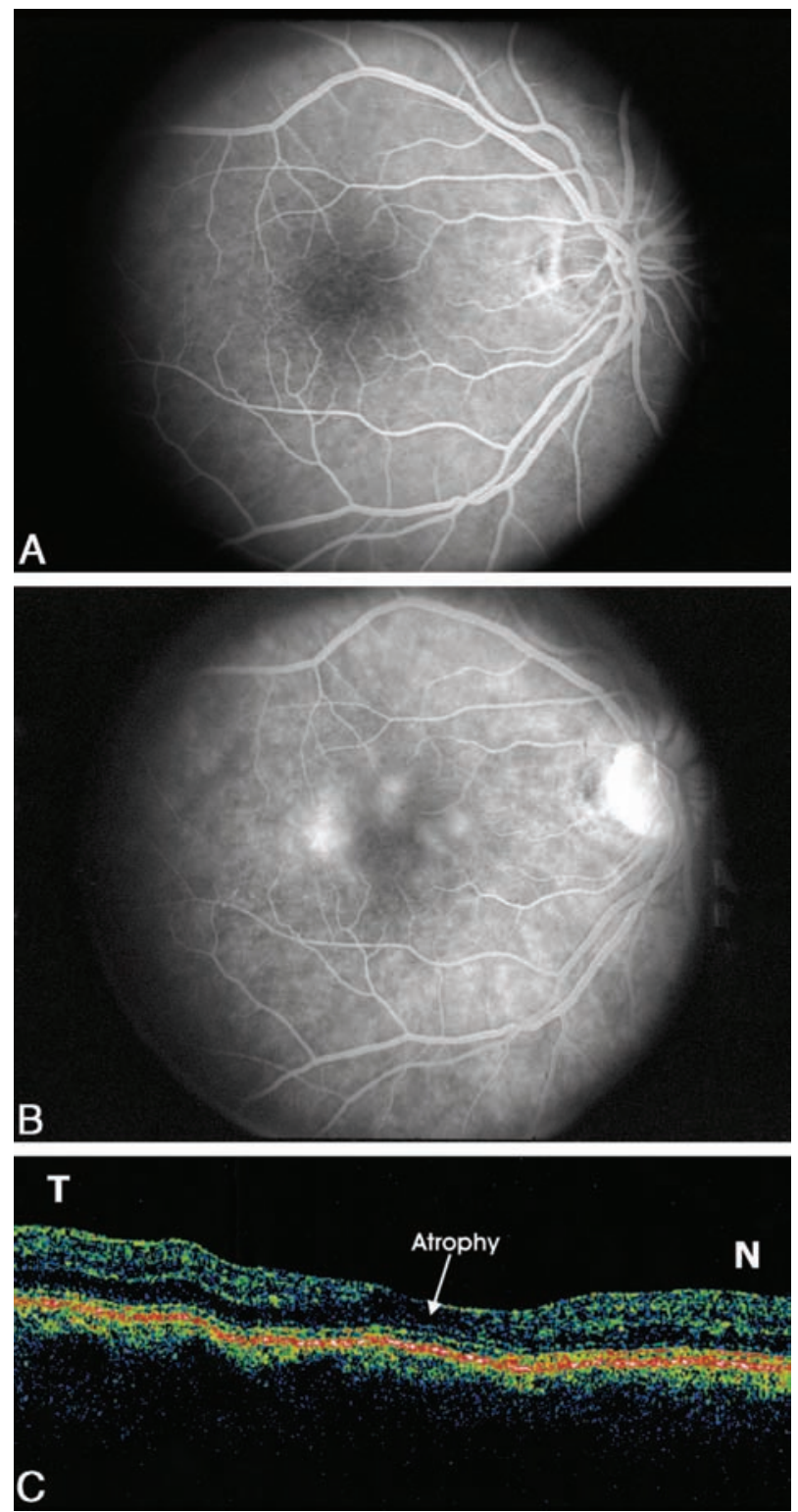

Fig. 1. A, B, Early and late fluorescein angiogram of an eye with stage 2 group 2a idiopathic juxtafoveal retinal telangiectasis. Temporal telangiectasis is evident in the early frames and then late temporal leakage sparing the fovea. $\mathbf{C}$, Optical coherence tomography horizontal line scan of the same eye shows minimal outer retinal atrophy.

eyes had thinning and loss of the normal architecture of the outer retina $(86 \%)$ (Figure 2, Table 3 ).

Stage 4 eyes $(\mathrm{n}=14)$ had dilated and blunted right-angle vessels $(100 \%)$ in addition to graying of the temporal retina $(100 \%)$, retinal crystals $(38 \%)$, and telangiectasis seen with slit lamp biomicroscopy and fluorescein angiography. All of these eyes had a black, superficial, stellate plaque, usually temporal to the fovea. The mean foveal thickness in these eyes was $191 \mu \mathrm{m}(93-253 \mu \mathrm{m})$. The OCT scans also showed hyper-reflective intraretinal plaques with shadowing that corresponded to the pigment plaque. In addition, all of these eyes had photoreceptor disruption and outer retinal atrophy. Most of these eyes had foveal cysts (64\%) with an average width of $200 \mu \mathrm{m}(75-700$ $\mu \mathrm{m})$ and an average height of $75 \mu \mathrm{m}(50-100 \mu \mathrm{m})$ (Figure 3, Table 3).

\section{Discussion}

The Gass staging of group 2a IJRT predates OCT. We included OCT in our staging of this disease because it reveals the microstructure of the retina in greater detail than can be perceived by even the most astute observer (Table 2). With its $10 \mu \mathrm{m}$ resolution, OCT can detect microscopic pockets of intraretinal and subretinal fluid. In retinal diseases, like group $2 \mathrm{a}$ IJRT, where leakage of fluorescein from retinal vessels is central to the disorder, OCT can be instrumental at delineating subtle pockets of intraretinal and subretinal fluid as well as structural alterations of the retinal layers.

We found intraretinal or subretinal pockets of fluid in 23 of 41 of the eyes in this study using OCT. Only six of these cysts were visible ophthalmoscopically. In one case, a central cyst evident on fundus examination was not present on OCT scanning. This eye had a pseudocyst that appeared at the edge of the circular parafoveal gray zone.

There are several reasons we included these cysts in the staging of nonproliferative group 2a IJRT (Table 2 ). First, the cysts likely represent an important stage in the disease evolution when there is a buildup of intraretinal or subretinal fluid and surrounding retinal atrophy. Second, these foveal cysts are readily detectable on OCT. Finally, eyes with detectable foveal cysts may respond to new treatments geared toward diseases like cystoid macular edema and central serous retinopathy where abnormal accumulations of fluid in or under the retina cause retinal damage and vision loss.

In their report, which included nine eyes with group 2a IJRT, Paunescu et al propose different names for OCT hyporeflective voids present at different retinal depths. ${ }^{13}$ A superficial hyporeflective void is called cystlike and ILM drape, and a deeper hyporeflective void is called a cyst, cystoid, and pseudo-cystoid. ${ }^{13}$ In our discussion we use the term cyst for all hyporeflective voids evident on OCT. In Table 3, we do separately report those voids Paunescu et al call ILM drapes. Nevertheless, we also include these ILM drape voids in our overall accounting of foveal cysts. Any eye with a foveal cyst evident on OCT was excluded from stage 1 and 2 disease in this study.

Group 2a IJRT has clinical, fluorescein angio- 
Fig. 2. A, Color fundus photograph of an eye with stage 3 group $2 \mathrm{a}$ idiopathic juxtafoveal retinal telangiectasis showing retinal crystals. B, C, Early and late fluorescein angiogram. Early frames show temporal parafoveolar telangiectasis with right-angle vessels. Late frames show leakage. D, Optical coherence tomography horizontal line scan of the same eye shows focal hyperreflective spot, deep retinal atrophy, and foveal cysts.
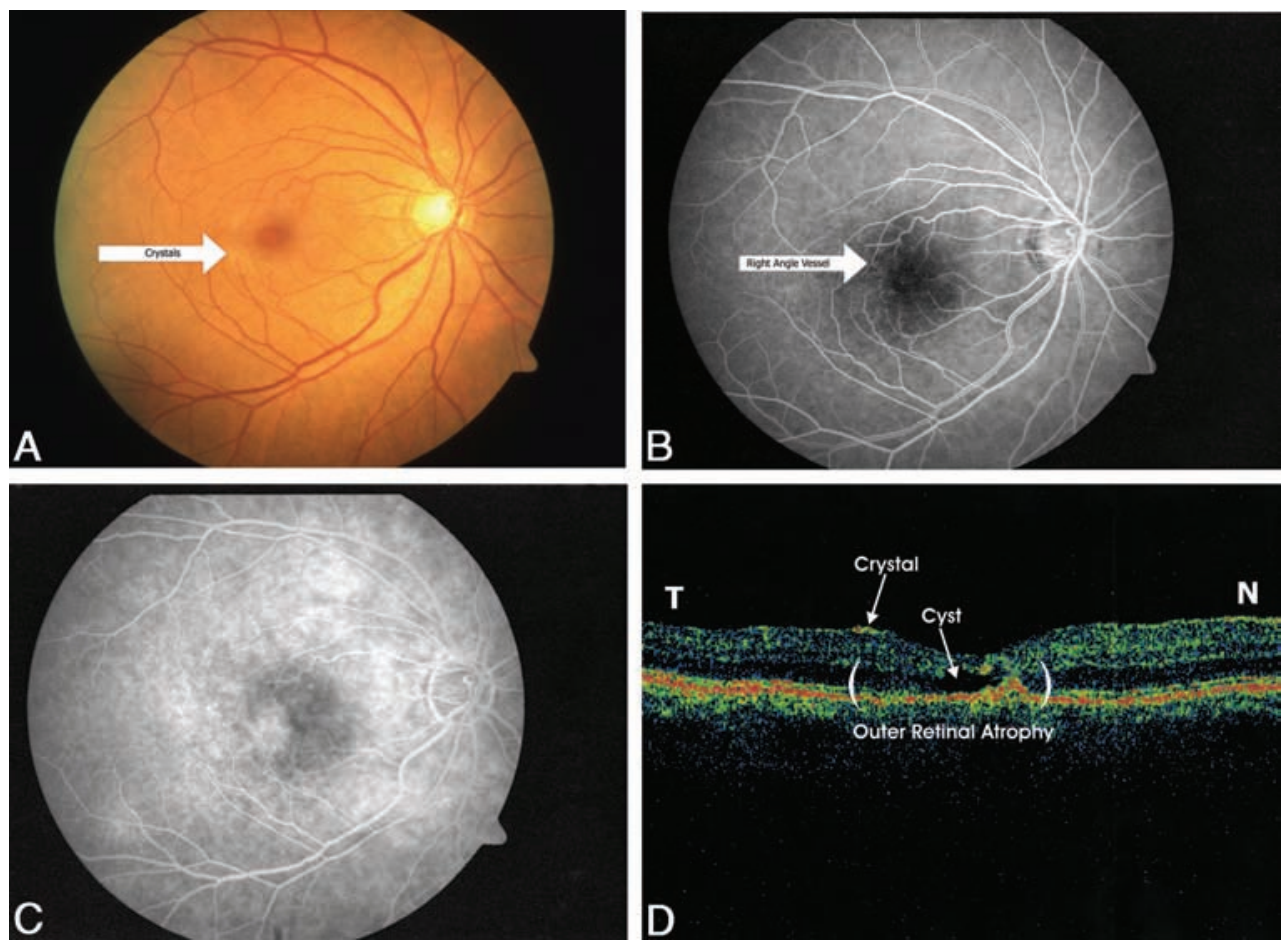

graphic, and OCT findings unlike other macular diseases. Although fluorescein angiography demonstrates leaky telangiectatic parafoveal vessels, OCT scanning does not demonstrate parafoveolar retinal cysts or parafoveolar retinal thickening. Although 23 eyes had foveal cysts, none had a thickened fovea. The average central foveal thickness in our 41 eyes was $166 \mu \mathrm{m}$ (31-264 $\mu \mathrm{m})$ (Table 3).

The pathogenesis of group 2a IJRT is controversial. Based on fluorescein angiographic findings, Gass initially suggested a primary role of the leaky retinal capillaries with subsequent chronic nutritional damage to Müller cells in eyes with group 2a IJRT. ${ }^{1}$ Later,
Gass commented that "this disorder (group 2a IJRT) is not primarily a leaky retinal blood vessel disease," but rather "the primary abnormality may reside in one or both of the parafoveolar retinal neural or Müller cells."14

In an attempt to increase the understanding of this disease, Green et al described the electron microscopic findings of one eye with probable group 2a IJRT. ${ }^{15}$ This clinical pathologic report showed intracellular and intercellular edema primarily in the inner retinal layers. Foveal cysts comparable to those seen on OCT were not described, and the integrity of the Müller cells was not noted. The primary electron
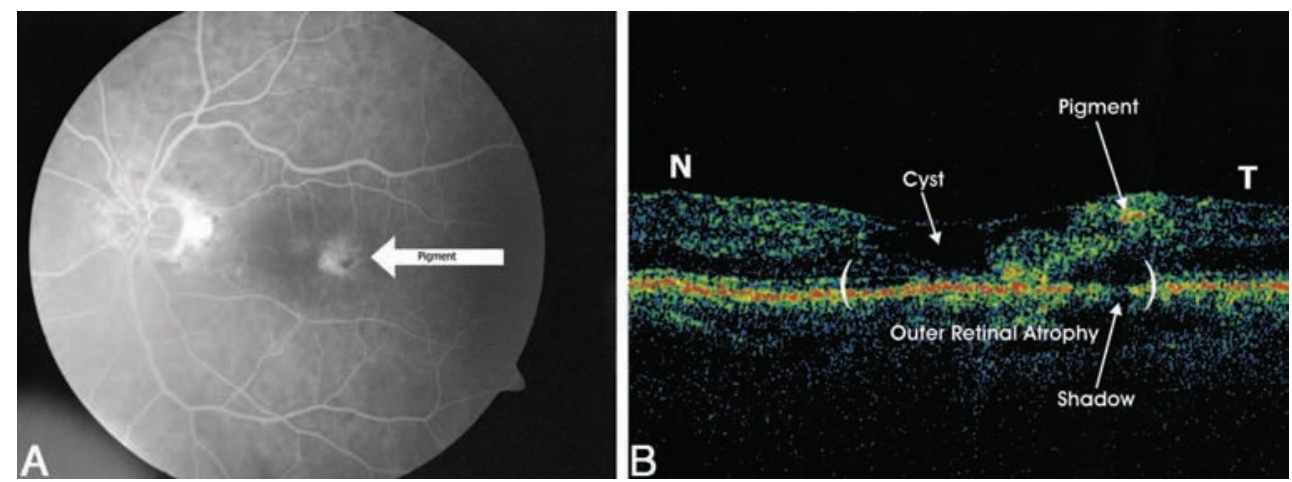

Fig. 3. A, Early fluorescein angiogram of an eye with stage 4 group 2a idiopathic juxtafoveal retinal telangiectasis. Hypofluorescent spot temporal to the fovea is the plaque of retinal pigment epithelial migrations and hyperplasia. Retinal capillaries are telangiectatic and incompetent. B, Optical coherence tomography horizontal line scan shows thinning of the outer retina, occult foveal cyst, and a broad superficial hyper-reflective area (pigment) with shadow. 
microscopy finding in this eye was capillary endothelial cell degeneration and regeneration. ${ }^{15}$ Interestingly, the unusual capillary endothelial abnormalities seen in this eye could be secondary to Müller cell dysfunction, since Müller cells in the retina, like astrocytes in the brain, are critical to proper function of the retinal capillary endothelium. ${ }^{16-19}$ A clinical pathologic report by Fine and Brucker of electron microscopy findings in eyes with cystoid macular edema nicely demonstrates the role of Müller cell swelling and necrosis in the pathogenesis of cystoid macular edema. ${ }^{20}$

The primary locus of group 2a IJRT, Müller cells, retinal neurons, or retinal capillaries, has yet to be determined. OCT offers a new opportunity to try to understand this puzzling retinal disease by correlating structural information gleaned from OCT with functional information gleaned from clinical examination and fluorescein angiography.

We propose that Müller cell dysfunction may explain the clinical, fluorescein angiogram, and OCT findings in patients with IJRT type 2a: retinal crystalline deposits, gray discoloration of the temporal parafoveal retina, parafoveal telangiectasis, retinal atrophy, black stellate superficial retinal plaques, foveal cysts, and subretinal neovascularization. Each of these findings and their possible relationship to Müller cell dysfunction is described below.

The retinal crystalline deposits in some eyes with IJRT, and not in any other retinal vascular disease, are thought to be the footplates of degenerated Müller cells. ${ }^{1}$ The composition of these crystalline deposits is unknown. Crystalline intracytoplasmic inclusions measuring $10 \mu \mathrm{m}$ to $40 \mu \mathrm{m}$ in diameter sometimes form in central nervous system astrocytes. ${ }^{21-24}$ These crystalline deposits are called Rosenthal fibers and form under chronic stress conditions. ${ }^{21-24}$

The gray discoloration of the temporal parafoveolar retina may be from ischemia and nutritional damage to the middle layers of the retina. The foveal and parafoveolar retina has the densest concentration of photoreceptors in the retina. The high metabolic activity of these photoreceptors requires high levels of oxygen and nutrients. The Müller cells, which help provide nutrition to retinal neurons, are relatively sparse in the parafoveolar retina. ${ }^{25} \mathrm{~A}$ similar gray discoloration of the retina has been reported in an eye recovering from a severe vascular occlusion. ${ }^{26}$ OCT did not reveal any abnormality in the area of gray discoloration. This suggests that the alterations in retinal structure in this gray zone are too subtle to be imaged using the current technology.

The parafoveolar telangiectasis and concomitant fluorescein leakage would be expected with breakdown of the capillary endothelial blood-retinal bar- rier. In addition to their structural role, Müller cells confer barrier properties to the retinal capillary endothelium and help regulate retinal blood flow. ${ }^{18,19}$ Since Müller cells maintain the integrity of the blood-retinal barrier, Müller cell degeneration or dysfunction would be accompanied by a breakdown of the blood-retinal barrier and the observable alterations in the parafoveolar retinal capillaries of patients with type $2 \mathrm{a}$ IJRT. ${ }^{18}$

The outer retinal atrophy seen with OCT in these eyes (Figures 2 and 3) could not be caused by retinal vascular abnormalities alone, because the outer retina derives oxygen and nutrients from the choriocapillaris, not the retinal circulation. Müller cell dysfunction, on the other hand, could lead to outer retinal atrophy and degeneration, because Müller cells maintain the health of the surrounding neurons including the outer retinal neurons (photoreceptors). ${ }^{19,25,27-29}$

The foveal cysts seen on OCT are not specifically mentioned in Gass' description of this disease. With slit lamp biomicroscopy, these areas, when visible, look like lamellar macular holes. They have a distinct, often circular, margin and central retinal thinning. These voids with adjacent retinal atrophy form within the boundaries of the foveal avascular zone (Figures $2-4)$. The voids were localized in the foveola in all 22 eyes and never extended beyond the edge of the capillary free zone. These intraretinal voids are unlike those seen in patients with macular edema caused by retinal vein occlusion, diabetes, and inflammation because they are not associated with increased retinal thickness. ${ }^{12}$

These voids probably represent pockets of intraretinal and subretinal fluid. OCT scans distinguish tissue layers based on their optical properties. Light used by the OCT scanner can be transmitted, absorbed, or scattered by retinal tissue. ${ }^{12}$ The intraretinal and subretinal dark zones seen in our patients represent areas where light is transmitted through the tissue with no backscattering. Given the reflective margins around these spaces, they probably represent intraretinal and rarely subretinal accumulations of fluid.

The accumulation of fluid in the fovea of these patients is unexpected and difficult to explain. The breakdown of the blood-retinal barrier occurs in the parafoveolar retinal capillaries. Therefore, one would expect a fluid accumulation in the parafoveal inner retina. Yet the OCT scans show pockets of fluid inside the foveal avascular zone that are sometimes deep and sometimes superficial (Figures 2-4). These localized patches of fluid may be caused by pertinacious fluid that leaks from the parafoveolar retinal capillaries and migrates to the fovea. Such proteinaceous fluid could accumulate within the foveal avascular zone because 

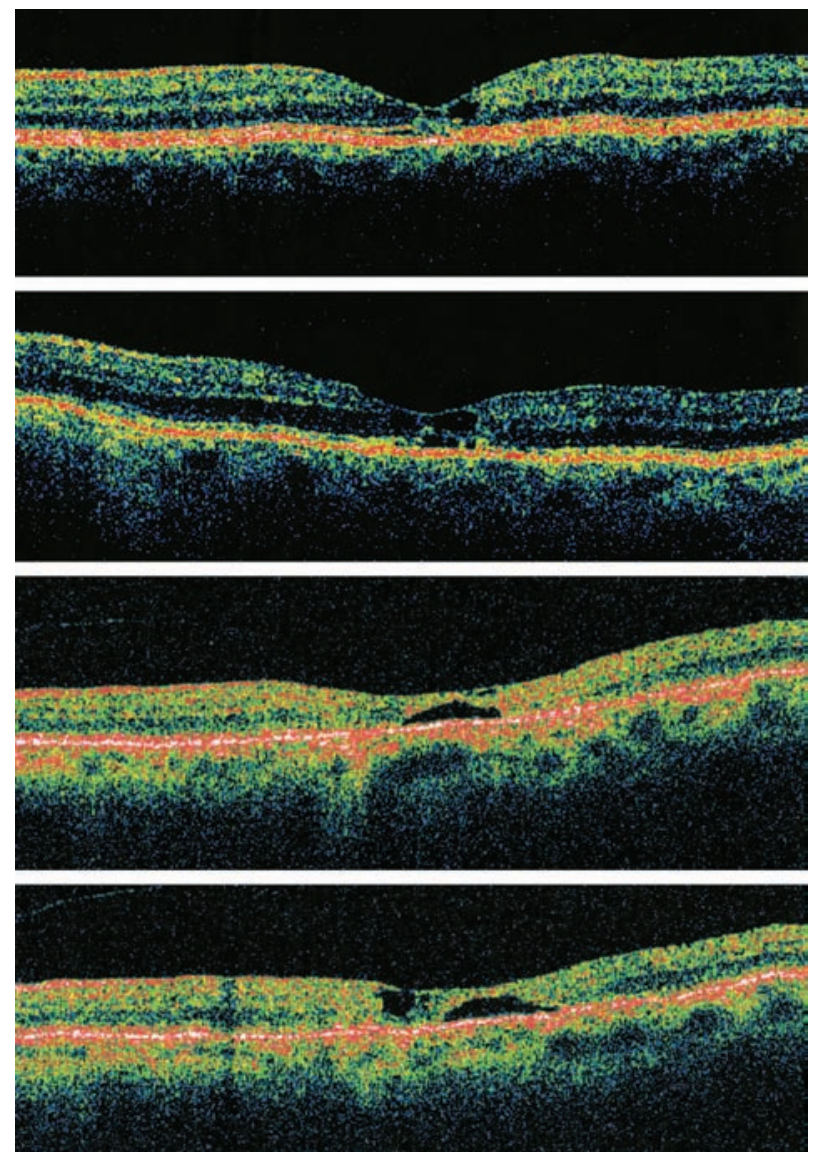

Fig. 4. Horizontal line scans (nasal retina to the left) of four eyes with stage 3 group 2a idiopathic juxtafoveal retinal telangiectasis. All eyes have foveal cysts at various retinal depths. Overall retinal thickness is normal.

of the lack of a capillary system there to remove them. The accumulation of fluid in the fovea of these patients suggests that the proteins responsible for the foveal intraretinal fluid pocket are not readily eliminated by the retinal pigment epithelium. Selective accumulation of subfoveal fluid is sometimes seen in patients after repair of macula-off retinal detachments and from distant retinal vascular disorders suggesting that the retinal circulation may play a role in the elimination of subretinal fluid in some situations. ${ }^{30,31}$

The black stellate plaques in stage 4 IJRT correspond to the broad hyper-reflective areas seen on OCT with shadowing (Figure 3). ${ }^{11}$ Migration of the retinal pigment epithelial cells into the retina and concomitant hyperplasia can occur in areas of progressive degeneration of the rods and outer retina. ${ }^{32}$ OCT documents degeneration of the outer retina in the areas of pigment migration.

OCT is a powerful new tool for evaluating macular disorders. In patients with group 2a IJRT, OCT reveals a new finding of occult foveal cysts without increased foveal thickness. OCT helps divide eyes with this disease into clinically important stages. When added to what is known about group 2a IJRT, OCT findings reported in this study support Gass' suggestion that the primary locus of disease in these eyes is the Müller cells. ${ }^{14}$ The occurrence of group $2 \mathrm{a}$ IJRT in identical twins and in two families suggests a possible genetic component to this disorder. ${ }^{33-35} \mathrm{We}$ propose that patients with group 2a IJRT may have defective Müller cells that selectively degenerate in the parafoveal area over time and eventually give rise to all of the abnormalities seen in this disease.

Key words: idiopathic juxtafoveal retinal telangiectasis, optical coherence tomography, macula, Müller cells, parafoveolar telangiectasis.

\section{References}

1. Gass JDM. Stereoscopic Atlas of Macular Disease, 4th ed. St. Louis, MO: Mosby, 1997;505-511.

2. Reese AB. Telangiectasis of the retina and Coats' disease. Am J Ophthalmol 1956;42:1-8.

3. Gass JD, Oyakawa RT. Idiopathic juxtafoveal retinal telangiectasis. Arch Ophthalmol 1982;100:769-780.

4. Gass JDM, Blodi BA. Idiopathic juxtafoveolar retinal telangiectasis: update of classification and follow-up study. Ophthalmology 1993;100:1536-1546.

5. Casswell AG, Chaine G, Ruch P, Bird AC. Paramacular telangiectasis. Trans Ophthalmol Soc UK 1986;105:683-692.

6. Abujamra S, Bonanomi MT, Cresta FB, et al. Idiopathic juxtafoveal retinal telangiectasis: clinical pattern in 19 cases. Ophthalmologica 2000;214:406-411.

7. Moisseiev J, Lewis H, Batov E, et al. Superficial retinal refractile deposits in juxtafoveal telangiectasis. Am J Ophthalmol 1990;109:604-605.

8. Davidorf FH, Pressman MD, Chambers RB. Juxtafoveal telangiectasis-a name change? Retina 2004;24:474-478.

9. Shahidi M, Wang Z, Zelkha R. Quantitative thickness measurement of retinal layers imaged by optical coherence tomography. Am J Ophthalmol 2005;139:1056-1061.

10. Pons ME, Garcia-Valenzuela E. Redefining the limit of the outer retina in optical coherence tomography scans. Ophthalmology 2005;112:1079-1085.

11. Trabucchi G, Brancato R, Pierro L, et al. Idiopathic juxtafoveolar retinal telangiectasis and pigment epithelial hyperplasia: an optical coherence tomographic study. Arch Ophthalmol 1999; 117:405-406.

12. Schuman JS, Puliafito CA, Gujimoto JG. Optical coherence tomography of ocular diseases. 2nd ed. Thorofare, NJ: Slack, 2004;24,113-139,140-147.

13. Paunescu LA, Ko TH, Duker JS, et al. Idiopathic juxtafoveal retinal telangiectasis: new findings by ultrahigh-resolution optical coherence tomography. Ophthalmology 2006;113: $48-57$.

14. Gass JDM. Histopathologic study of presumed parafoveal telangiectasis. Retina 2000;20:226-227.

15. Green WR, Quigley HA, De La Cruz Z, Cohen B. Parafoveal retinal telangiectasis, Light and electron microscopy studies. Trans Ophthalmol Soc UK 1980;100:162-170.

16. Janzer RC, Raff MC. Astrocytes induce blood-brain barrier properties in endothelial cells. Nature 1987;325:253-257. 
17. Haseloff RF, Blasig IE, Bauer HC, et al. In search or the astrocytic factor(s) modulating blood-brain barrier functions in brain capillary endothelial cells in vitro. Cell Mol Neurobiol 2005;25:25-39.

18. Tout S, Chang-Ling T, Hollander H, Stone J. The role of Müller cells in the formation of the blood-retinal barrier. Neuroscience 1993;55:291-301.

19. Newman E, Reichenbach A. The Müller cell: a functional element of the retina. Trends Neurosci 1996;19:307-312.

20. Fine BS, Brucker AJ. Macular edema and cystoid macular edema. Am J Ophthalmol 1981;92:466-481.

21. Hagemann TL, Gaeta SA, Smith MA, et al. Gene expression analysis in mice with elevated glial fibrillary acidic protein and Rosenthal fibers reveals a stress response followed by glial activation and neuronal dysfunction. Hum Mol Genet 2005; 14:2443-2458.

22. Castellani RJ, Perry G, Harris PL, et al. Advanced lipid peroxidation end-products in Alexander's disease. Brain Res 1998;787:15-18.

23. Iwaki T, Iwaki A, Tateishi J, et al. Alpha B-crystallin and $27-\mathrm{kd}$ heat shock protein are regulated by stress conditions in the central nervous system and accumulate Rosenthal fibers. Am J Pathol 1993;143:487-495.

24. Gray F, DeGirolami U, Poirier J. Escourolle \& Poirier Manual of Basic Neuropathology. 4th ed. Philadelphia: Butterworth-Heinemann, 2004;11.

25. Nishikawa S, Tamai M. Müller cells in the human foveal region. Curr Eye Res 2001;22:34-41.
26. Cherny M, O’Day J, Currie J. Intraretinal gray lesions as a sign of reversible visual loss following prolonged ophthalmic artery hypoperfusion. J Clin Neuro-ophthalmol 1991;11:228 232.

27. Cogan DG, Kuwabara T. The mural cell in perspective. Arch Ophthalmol 1967;78:133-139.

28. Bringmann A, Reichenbach A. Role of Müller cells in retinal degenerations. Frontiers Bioscience 2001;6:E72-92.

29. Jablonski MM, Iannaccone A. Targeted disruption of Müller cell metabolism induces photoreceptor dysmorphogenesis. Glia 2000;32:192-204.

30. Otani T, Yamaguchi Y, Kishi S. Serous macular detachment secondary to distant retinal vascular disorders. Retina 2004; 24:758-762.

31. Hagimura N, Iida T, Suto K, Kishi S. Persistent foveal retinal detachment after successful rhegmatogenous retinal detachment surgery. Am J Ophthalmol 2002;133:516-520.

32. Duke-Elder S, Dobree JH. System of Ophthalmology. Diseases of the Retina, Vol X. London: Henry Kimpton, 1967; 598.

33. Siddiqui N, Fekrat S. Group 2a Idiopathic juxtafoveolar retinal telangiectasia in monozygotic twins. Am J Ophthalmol 2005; 139:568-570.

34. Oh KT, Park DW. Bilateral juxtafoveolar telangiectasis in a family. Retina 1999;19:246-247.

35. Hutton WL, Snyder WB, Fuller D, Vaiser A. Focal parafoveal retinal telangiectasis. Arch Ophthalmol 1978;96:13621367. 